\title{
Strength of Reactive Powder Concrete Beam-Column Joints Reinforced with High-Strength (HRB600) Bars under Seismic Loading
}

\author{
D. H. Wang, ${ }^{\text {ab, }, 1}$ Y. Z. Ju, ${ }^{b}$ and W. Z. Zheng ${ }^{a}$ \\ ${ }^{a}$ Key Lab of Structures Dynamic Behavior and Control of the Ministry of Education, Harbin Institute \\ of Technology, Harbin, China \\ ${ }^{b}$ School of Civil Engineering and Architecture, Northeast Electric Power University, Jilin, China \\ ${ }^{1}$ hitwdh $(0) 126 . \mathrm{com}$
}

In order to study the seismic behavior of reactive powder concrete beam-column joints reinforced with high-strength bars, an experimental investigation was carried out. A total of 5 reinforced reactive powder concrete exterior joint specimens (including 2 specimens with HRB600 steel bars and 3 specimens with HRB400 steel bars) were cast and tested. The seismic behavior of 5 existing test specimens was studied, including failure mode, hysteretic behavior, deformation capacity, ductility, energy dissipation capacity, and strength and stiffness degradation. The results showed that failure modes of reactive powder concrete beam-column joints under reversed cyclic loading are mainly flexural failure of the beam adjacent to the joint core, shear failure of the joint core, or combined failure of the plastic hinge in the beam and shear in the joint core. The configuration of HRB600 bars in reactive powder concrete beam-column joints alleviates the destruction, reduces the degradation of strength and stuffness, lessens residual deformation, and enhances both deformation capacity and energy dissipation capacity. Stirrups in the joint core directly bear part of the shear forces and provide confinement to the reactive powder concrete. Therefore, the utilization of stirrups in joints can retard the development of diagonal cracks, slow the degradation of strength and stuffness, and enhance the bearing capacity and energy dissipation capacity of the joint.

Keywords: reactive powder concrete, exterior beam-column joint, HRB600 and HRB400 steels, seismic behavior.

Introduction. The use of high-strength reinforcement bars not only increases resource utilization, thus reducing pollution, but also reduces the consumption of reinforcement bars, thus facilitating construction [1,2]. Although the code for the design of concrete structures (GB 50010-2010) in China specifies the use of HRB500 steel bars [3], a higher-strength HRB600 steel bar has been developed [4]. The yield strain of HRB600 bars ranges from 0.0035 to 0.0043 , which is 30 to 50 percent higher than that of HRB400 steel bars. The elasticity modulus of HRB600 bars ranges from $1.89 \mathrm{GPa}$ to $1.95 \mathrm{GPa}$, which is less than that of HRB400 and HRB500 bars. Therefore, the use of HRB600 bars can enhance the deformation capacity of reinforced concrete frame structures, which is favorable for the seismic performance of structural elements.

If high-strength steel bars are applied to reactive powder concrete structures with high strength, cracking resistance, toughness and durability [5-8], the combined advantages of the two materials can significantly improve the security and durability of structures. Most studies have focused on normal concrete frame joints reinforced with $400 \mathrm{MPa}$ grade steel bars or FRP bars [9-11], but little research has been conducted on the seismic behavior of reactive powder concrete frame joints reinforced with high-strength steel bars. Owing to a lack of test data, none of the current concrete design codes and guidelines (Chinese Standards GB 50010-2010, ACI 2014, BS EN 1998-1: 2004 Eurocode 8) [3, 9] provide any recommendations on the seismic design of reactive powder concrete beam-column frame joints when HRB600 bars are used as the primary reinforcement $[3,12,13]$. 
In this study, two exterior reactive powder concrete joints with HRB600 bars and three with HRB400 bars were subjected to simulated seismic loading to investigate their seismic behavior, including seismic failure mode, deformation capacity, energy dissipation capacity, strength and stiffness degradation and stirrup strains.

1. Test Program.

1.1. Design Details of Specimens. Five exterior beam-column joints of a reinforced concrete frame structure, isolated at the inflection points of both the beam and column, were designed and constructed. Specimens EJ-4EA-0, EJ-4EA-1, and EJ-4ES-0 were reinforced with conventional HRB400 bars, while the remaining two specimens, EJ-6E-0 and EJ-6E-1, were reinforced with high-strength HRB600 bars. In the specimen names, EJ represents the exterior joint. $4 \mathrm{E}$ and $6 \mathrm{E}$ represent the $\mathrm{HRB} 400 \mathrm{E}$ and $\mathrm{HRB} 600 \mathrm{E}$ strength grades of the longitudinal reinforcements in the beam, respectively. 4EA and 4ES represent longitudinal HRB400E reinforcements that, compared to the HRB600E reinforcements, had either the same area or the same strength, respectively. The numbers 0 and 1 represent the number of stirrups in the joint core. The strength grade of the longitudinal reinforcement in the column is the same as a beam; the stirrups of all specimens are rectangular D6 HPB300 reinforced bars. Mechanical properties of the reinforcing bars are shown in Table 1. Table 2 shows the parameters of the specimens. Figure 1 shows the design details of the specimens. The design value of the axial compression ratio is 0.3 .

$\mathrm{T}$ a b 1 e 1

Mechanical Properties of Reinforcing Bars

\begin{tabular}{|c|c|c|c|c|}
\hline Grade of bar & $\begin{array}{c}\text { Diameter of bar } \\
(\mathrm{mm})\end{array}$ & $\begin{array}{c}\text { Yield strength } \\
(\mathrm{MPa})\end{array}$ & $\begin{array}{c}\text { Tensile strength } \\
\text { (MPa) }\end{array}$ & $\begin{array}{c}\text { Elastic modulus } \\
\text { (GPa) }\end{array}$ \\
\hline HRB600E & 14 & 651.0 & 861.7 & 1.95 \\
HRB400E & 20 & 441.9 & 588.6 & 2.00 \\
HRB400E & 14 & 455.8 & 625.9 & 2.00 \\
HPB300 & 10 & 360.6 & 522.2 & 2.01 \\
HPB300 & 6 & 353.6 & 398.3 & 2.10 \\
\hline
\end{tabular}

$\mathrm{T}$ a b 1 e 2

Details of Specimens

\begin{tabular}{|c|c|c|c|c|c|}
\hline $\begin{array}{c}\text { Specimen } \\
\text { number }\end{array}$ & $\begin{array}{c}f_{\mathrm{cu}} \\
\mathrm{MPa})\end{array}$ & $\begin{array}{c}\text { Steel bar } \\
\text { grade }\end{array}$ & $\begin{array}{c}\text { Longitudinal } \\
\text { bars in column }\end{array}$ & $\begin{array}{c}\text { Longitudinal } \\
\text { tensile bars } \\
\text { in beam }\end{array}$ & $\begin{array}{c}\text { Stirrups } \\
\text { of joint core }\end{array}$ \\
\hline EJ-4EA-0 & 118 & HRB400E & $\begin{array}{c}\text { Four } 14 \mathrm{~mm} \\
\text { diameter }\end{array}$ & $\begin{array}{c}\text { Three } 14 \mathrm{~mm} \\
\text { diameter }\end{array}$ & None \\
\hline EJ-4EA-1 & 113 & HRB400E & $\begin{array}{c}\text { Four } 14 \mathrm{~mm} \\
\text { diameter }\end{array}$ & $\begin{array}{c}\text { Three } 14 \mathrm{~mm} \\
\text { diameter }\end{array}$ & $\begin{array}{c}\text { One } 6 \mathrm{~mm} \\
\text { diameter }\end{array}$ \\
\hline EJ-4ES-1 & 115 & HRB400E & $\begin{array}{c}\text { Four } 14 \mathrm{~mm} \\
\text { diameter }\end{array}$ & $\begin{array}{c}\text { Twm } 20 \\
\text { mone } 10 \mathrm{~mm} \\
\text { diameter }\end{array}$ & $\begin{array}{c}\text { One } 6 \mathrm{~mm} \\
\text { diameter }\end{array}$ \\
\hline EJ-6E-0 & 113 & HRB600E & $\begin{array}{c}\text { Four } 14 \mathrm{~mm} \\
\text { diameter }\end{array}$ & $\begin{array}{c}\text { Three } 14 \mathrm{~mm} \\
\text { diameter }\end{array}$ & None \\
\hline EJ-6E-1 & 116 & HRB600E & Four $14 \mathrm{~mm}$ & $\begin{array}{c}\text { Three } 14 \mathrm{~mm} \\
\text { diameter }\end{array}$ & One 6 mm \\
diameter \\
\hline
\end{tabular}




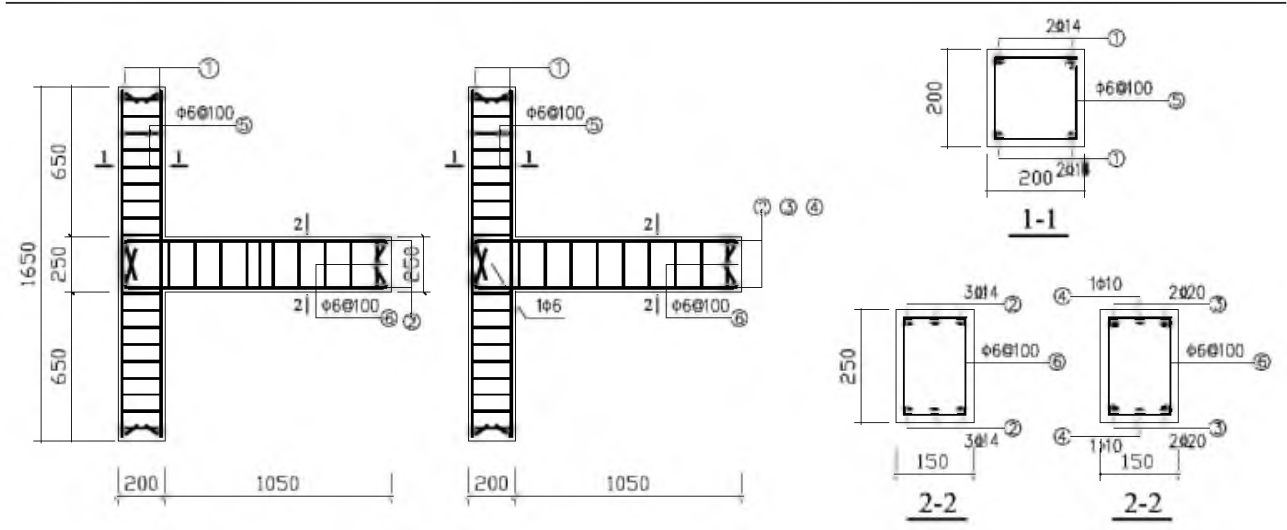

Fig. 1. Design details of specimens.

1.2. Test Setup and Loading Scheme. Figure 2 is the schematic diagram of the test setup. The top of the column was subjected to constant loading $(N)$ during the test process. The beam tip was subjected to reverse cyclic loading $(P)$. Hinged supports were located at the bottom end and top of the column. The compressive load $(N)$ was applied on the column top by a $2000 \mathrm{kN}$ hydraulic jack; the plunger of the jack was connected to the load cell to stabilize it.

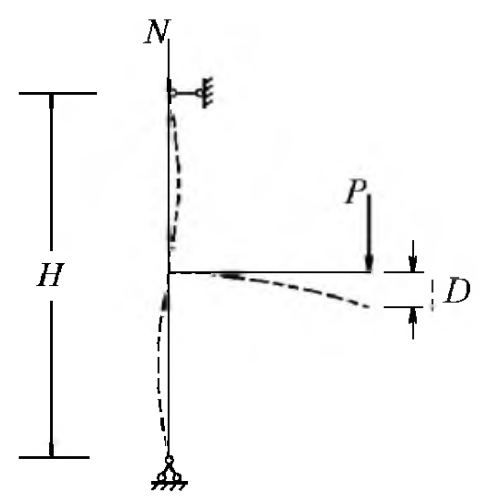

a

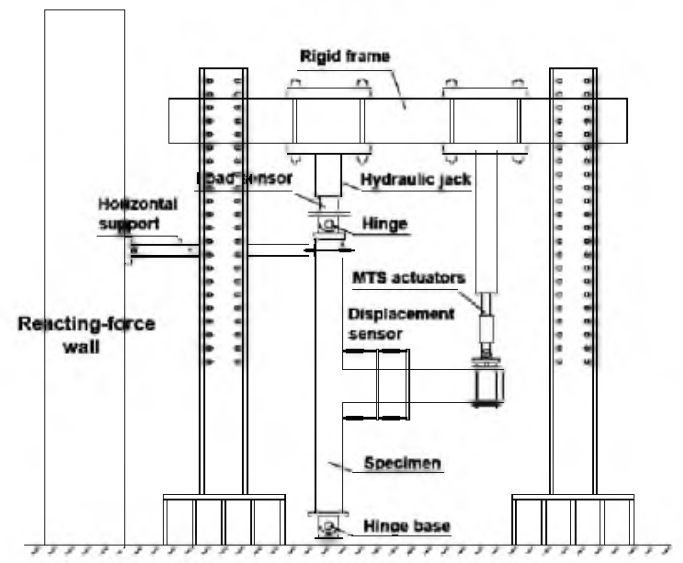

$\mathrm{b}$

Fig. 2. Schematic diagram of the test setup: (a) loading scheme; (b) loading equipment.

The reverse cyclic loading was applied to the beam tip using an MTS electrohydraulic servo actuator. The load history of the beam tip was determined based on Chinese code JGJ101-96 [14], which includes a force control phase and a deformation control phase, as shown in Fig. 3. During the force control phase, the load increased by $5 \mathrm{kN}$ each cycle. When shear cracks occurred in the joint core or when the longitudinal reinforcements in the beam yielded, the cyclic loading arrangement was switched to the deformation control phase. The deformation value is the defined yield deformation $\Phi_{y}\left(\Phi_{y}=\delta / L\right.$, where $\delta$ is the vertical displacement of the beam tip and $L$ is the length of the beam) During the deformation control phase, the ends of the beam tip were subjected to load cycles at the levels of $\Phi_{y}, 1.5 \Phi_{y}, 2 \Phi_{y}, 2.5 \Phi_{y}$, and so on. Three cycles were imposed at each deformation level. The test was continued until the load sustained had decreased to $85 \%$ of the maximum measured load strength. 


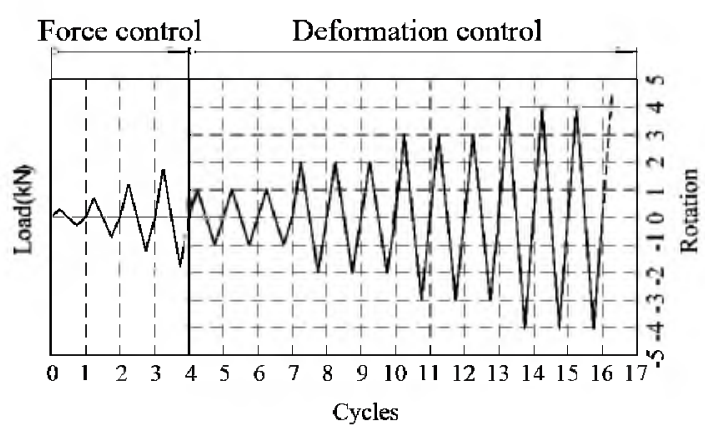

Fig. 3. The test loading process.

1.3. Instrumentation. The measured quantities included beam and column end force, beam end deformation, rotation angle, strains of the stirrup in the joint core and the longitudinal reinforcements in the beam, and the width of the crack in the joint core. The axial compression force at the column end was measured by a $2000 \mathrm{kN}$ load sensor. The force and deformation at the beam end were measured by the load and displacement sensor in the MTS. The strains of the stirrup in the joint core and the longitudinal reinforcements in the beam were measured using electrical resistance strain gauges; the locations of the gauges are shown in Fig. 4. In order to measure average strain, two strain gauges were symmetrically attached to both sides of the longitudinal reinforced bars.

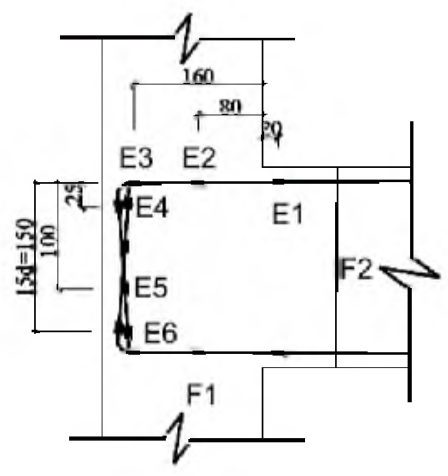

a

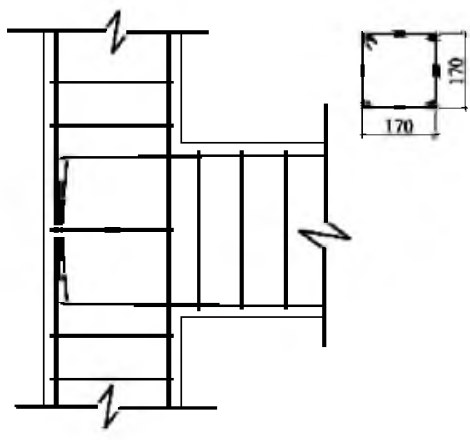

b

Fig. 4. Location of strain gauges on reinforced bar: (a) longitudinal bars in beam; (b) stirrups in joint core.

\section{Experimental Results and Analysis}

2.1. Experimental Results. Five types of specimens were tested as shown in Fig. 5.

2.1.1. Specimen EJ-4EA-0. At downward $19 \mathrm{kN}$ force, the first flexural crack appeared in the beam at a distance of $125 \mathrm{~mm}$ from the column interface; the crack width was about $0.02 \mathrm{~mm}$. At $25 \mathrm{kN}$ upward force, two new cracks were observed on the bottom of the beam, with a maximum crack width of about $0.04 \mathrm{~mm}$. New cracks appeared in the beam constantly with the increase of the load up to $40 \mathrm{kN}$; at that time, the average spacing between cracks was approximately $45 \mathrm{~mm}$. Yielding of the beam's longitudinal bars was first observed in the top beam reinforcement at $40 \mathrm{kN}$ downward (positive) force; the corresponding downward (positive) displacement was $17.2 \mathrm{~mm}$. The longitudinal bars in the bottom beam reinforcement yielded when upward (negative) force was $45 \mathrm{kN}$, while the corresponding displacement was $16.4 \mathrm{~mm}$. This marked the end of the force control stage. 


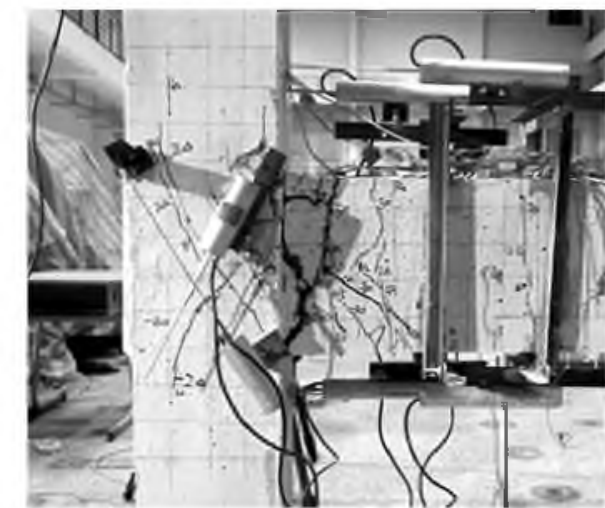

a

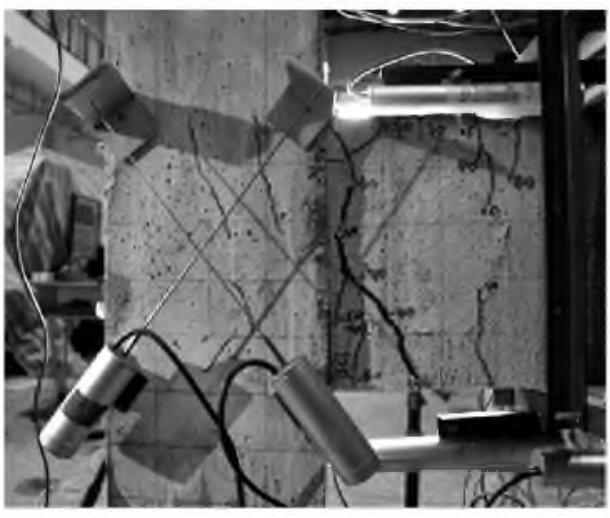

b

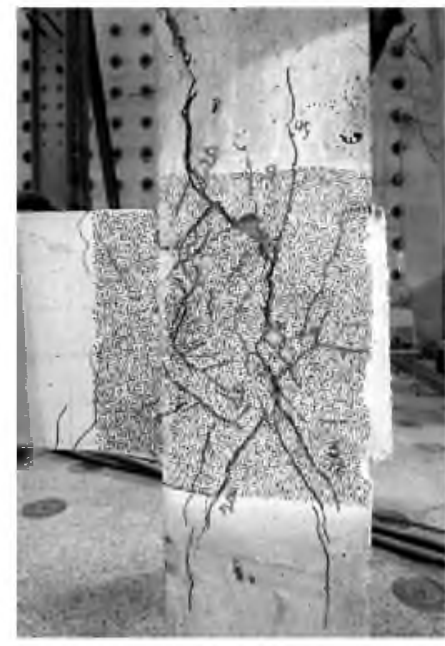

$\mathrm{C}$

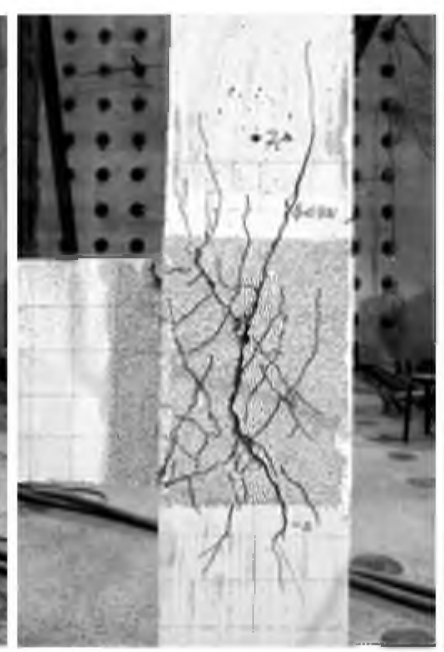

d

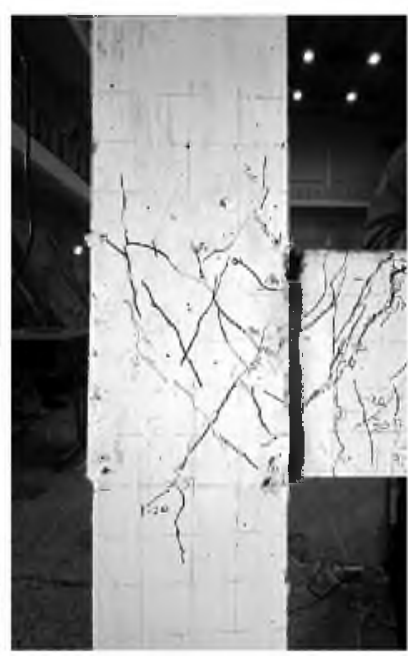

e

Fig. 5. Failure mode of specimens: (a) EJ-4EA-0 flexural failure in beam; (b) EJ-4EA-1 flexural failure in beam; (c) EJ-4ES-1 shear failure in joint area; (d) EJ-6E-0 shear failure in joint area; (e) EJ-6E-1 shear failure in joint area.

During the $\Phi_{y}$ deformation control stage, there was no obvious change in the existing cracks in the beam, and no new cracks occurred. At $\Phi_{y}=2.14 \%$, corresponding to the initial cracking strength of $51.2 \mathrm{kN}$, the first diagonal crack appeared in the joint core. The first diagonal crack was located in the center of the joint core and was parallel with the diagonal. Another crack formed along a different orthogonal diagonal direction at upward $2 \Phi_{y}$. Some diagonal cracks appeared in the joint core in the second and third cycles of $2 \Phi_{y}$. During the $3 \Phi_{y}$ stage, no new diagonal cracks appeared and there was less extension of the original diagonal cracks in the joint core, but the beam cracks became unstable. The crack widths increased quickly, accompanied by the spalling of a small quantity of concrete in the compression zone due to crushing. During the $4 \Phi_{y}$ stage, diagonal cracks in the joint core developed rapidly and eventually extended to diagonal corners, with a maximum measured crack width of $0.78 \mathrm{~mm}$.

2.1.2. Specimen EJ-4EA-1. Similar to specimen EJ-4EA-0, the first downward (positive) $20 \mathrm{kN}$ force caused a flexural crack in the beam at a distance of $150 \mathrm{~mm}$ from the column side. When the specimen was subjected to the downward $25 \mathrm{kN}$ force, a second crack was observed in the beam at a distance of $140 \mathrm{~mm}$ from the column side. At $25 \mathrm{kN}$ 
upward (negative) force, the first crack was observed on the bottom of the beam. Three new increasing cracks in the beam were observed at downward $30 \mathrm{kN}$ force, with a maximum crack width of about $0.1 \mathrm{~mm}$. Average strains at locations $F 1$ and $F 2$ (see Fig. 4a) quickly increased to $1156 \cdot 10^{-6}$ and $1061 \cdot 10^{-6}$, respectively, at upward (negative) $35 \mathrm{kN}$ force. In addition, four new cracks were observed in the beam, and the width of existing cracks increased. When the load increased to $40 \mathrm{kN}$, average strains at locations $E 1$ and $E 2$ further increased to $1980 \cdot 10^{-6}$ and $1193 \cdot 10^{-6}$, respectively, and the maximum crack width increased to $0.14 \mathrm{~mm}$. In subsequent loading, strains at location $E 1$ eventually reached $3360 \cdot 10^{-6}$ at downward $55 \mathrm{kN}$ force, and strains at location $F 1$ exceeded $3400 \cdot 10^{-6}$ at upward $60 \mathrm{kN}$ force, indicating that longitudinal reinforcements in the beam top and in the beam had all yielded. Initial cracks in the joint core formed along orthogonal diagonal directions. Cracks in the beam further widened during the early deformation control stage. When $\Phi_{y}=3.14 \%$, cracks in the beam developed faster and the maximum width increased to $2.4 \mathrm{~mm}$. With the increase of loading deformation and load cycle, the widths of cracks in the beam end adjacent to the joint significantly increased, spalling of a small quantity of concrete occurred under compression due to crushing, and a plastic hinge formed in the beam adjacent to the joint core.

2.1.3. Specimen EJ-4ES-1. The first downward $25 \mathrm{kN}$ force caused a flexural crack in the beam at a distance of $100 \mathrm{~mm}$ from the column side. At upward $25 \mathrm{kN}$ force, one crack was observed on the bottom beam. At downward $35 \mathrm{kN}$ force, the first diagonal crack in the joint core occurred, along with the increase of flexural cracks in the beam. One diagonal crack along a different diagonal direction was observed in the joint core at upward $50 \mathrm{kN}$ force. The loading method was then switched to deformation control. During the $\Phi_{y}$ stage, no changes were observed in the existing cracks in the beam and joint. During the $2 \Phi_{y}$ stage, flexural cracks in the beam widened significantly, but diagonal cracks in the joint extended and widened only slightly. During the $3 \Phi_{y}$ stage, a number of small diagonal cracks occurred along the two orthogonal diagonal directions; the main diagonal cracks widened and propagated toward the upper and lower columns, followed by the spalling of concrete on the edges of the main cracks.

2.1.4. Specimen $E J-6 E-0$. The first flexural crack in the top of the beam was observed at downward $17 \mathrm{kN}$ force, and the first flexural crack in the bottom of the beam was observed at upward $20 \mathrm{kN}$ force. Two parallel diagonal fine cracks were observed in the center position of the joint core at downward $35 \mathrm{kN}$ force. One diagonal crack along a different diagonal direction developed in the joint core at upward $48 \mathrm{kN}$ force. During the $\Phi_{y}$ stage, the cracks in the beam and joint core did not exhibit obvious changes. Some small diagonal cracks occurred in the joint core, while the main diagonal cracks extended toward the upper and lower column tips at the first cycle of $2 \Phi_{y}$; the maximum crack width reached $2.56 \mathrm{~mm}$. With the further increase of load deformation, the number of cracks in the column and the diagonal crack width in the joint core markedly increased, while the steel fibers bridging across the main cracks were partially pulled out. Spalling of concrete occurred on the edges of the cracks due to crushing. Eventually, the specimen exhibited shear failure.

2.1.5. Specimen EJ-6E-1. Similar to specimen EJ-6E-0, the first flexural cracks in the top and bottom of the beam occurred at $20 \mathrm{kN}$ force directed downward and upward, respectively. The first diagonal crack was observed at downward $43 \mathrm{kN}$ force; the corresponding downward deformation was $2.2 \%$. The first diagonal crack along a different diagonal direction in the joint core was seen at upward $45 \mathrm{kN}$ force. The loading method was then switched to deformation control. During the deformation control stage, the strain of the longitudinal reinforcement exceeded $2800 \cdot 10^{-6}$, the yield strain of the steel bars. At this stage, an inconspicuous plastic hinge formed in the beam adjacent to the joint edge. As compared with specimen EJ-6E-0, specimen EJ-6E-1 had higher initial cracking strength and the failure cracks were less wide due to the configuration of the stirrup. 
2.2. Hysteretic Curves. Figure 6 shows the force versus rotation relations of reinforced reactive powder concrete specimens tested under reversed cyclic loading. It can be observed from Fig. 6 that two different kinds of hysteretic curves were generated, depending on the type of failure that occurred in the specimen: flexural failure of the beam or shear failure of the joint core.
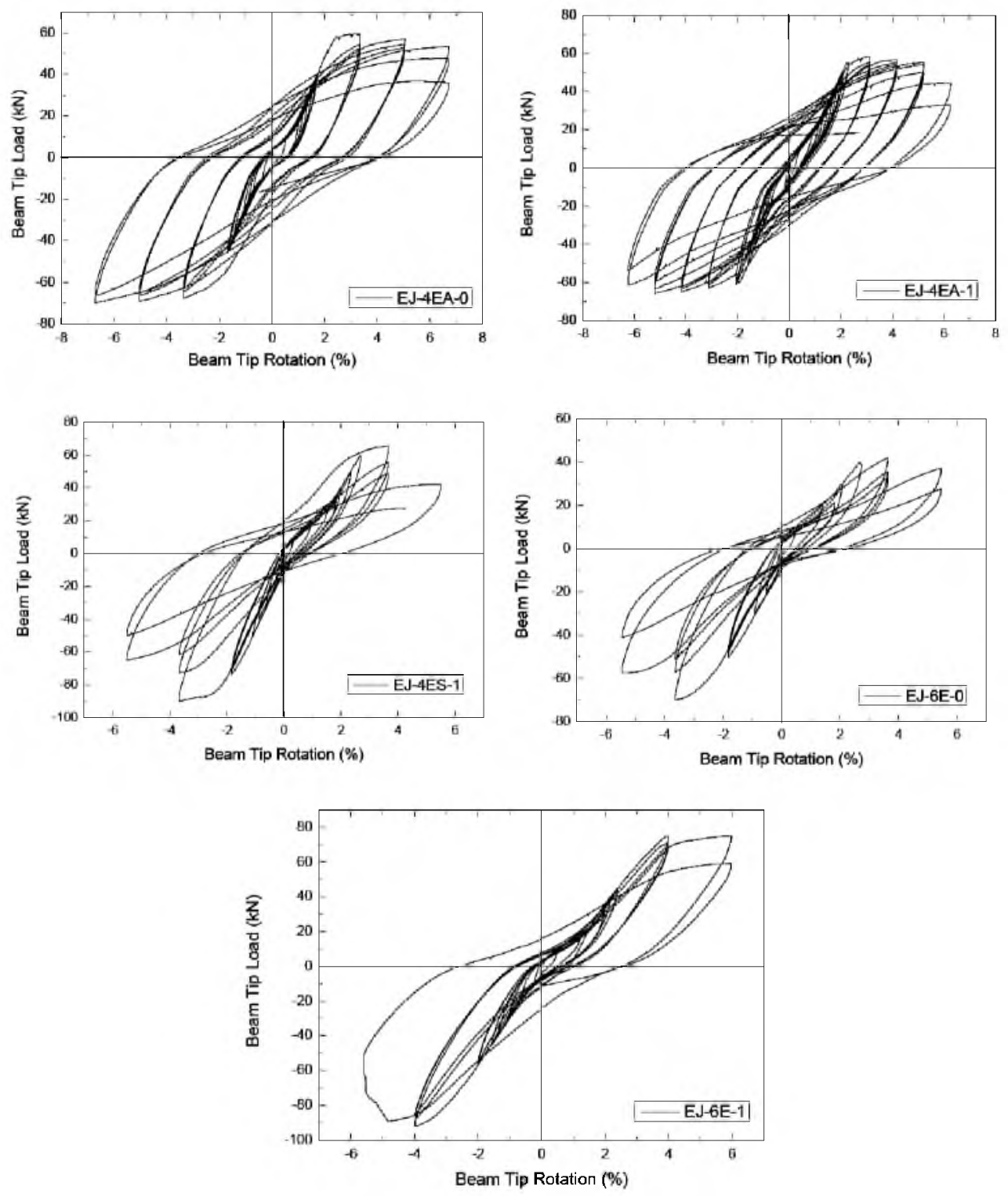

Fig. 6. Load-rotation hysteresis curves of specimens.

(1) Specimens EJ-4EA-0 and EJ-4EA-1, which exhibited plastic hinge failure in the beam, have similar hysteretic curves. During the early loading stage, when specimens were in the elastic stage, the hysteretic curve is approximately linear, indicating the absence of residual deformation when unloading. With the increase of the cyclic load at the free end of the beam, the area enclosed by the load-deformation hysteretic curve increases gradually, and the hysteretic loops do not show obvious pinching. 
(2) Specimens EJ-4ES-1, EJ-6E-0, and EJ-6E-1 all showed shear failure in the joint core. Load-deformation hysteretic loops resemble a stable bow shape and indicate relatively low residual deformation when unloading, before cracking of reactive powder concrete occurred in the joint core. As the level of displacement and loading increased after cracking, the degradation of stiffness and strength can be observed in the hysteretic curve, as well as residual deformation, which results in less pinching of the hysteretic curve. Compared with other specimens, the curve of EJ-6E-1 showed less pinching, which can be attributed to the inconspicuous plastic hinge formation in the beam adjacent to the joint core. The shear bearing capacity of specimen EJ-6E-1 was higher than those of other specimens due to the configuration of the stirrup in the joint core.

(3) As compared with specimen EJ-4ES-1, specimens EJ-6E-0 and EJ-6E-1 had higher seismic deformation capacity and ductility, and exhibited slower degradation of stiffness and strength.

2.3. Ductility. The ductility performance of structures or components can be characterized by the ductility factor [14]; the displacement ductility factor $\mu_{\Delta}$ is adopted in this paper to characterize the ductility of reinforced reactive powder concrete frame joints. Considering partial asymmetry of the hysteretic curve for specimens, the displacement ductility factor is defined as

$$
\mu_{\Delta}=\left(\left|+\Delta_{u}\right|+\left|-\Delta_{u}\right|\right) /\left(\left|+\Delta_{y e}\right|+\left|-\Delta_{y e}\right|\right),
$$

where $\Delta_{u}$ is the ultimate displacement corresponding ultimate load $P_{u}$. The yield displacement $\Delta_{y e}$ can be computed through the energy method, and the corresponding yield load is $P_{y e}[15]$.

$\mathrm{T}$ a b 1 e 3

Ductility Factor of Specimens

\begin{tabular}{|c|c|c|c|c|c|c|}
\hline $\begin{array}{c}\text { Specimen } \\
\text { number }\end{array}$ & $\begin{array}{c}\text { Direction } \\
\text { of load }\end{array}$ & $\begin{array}{c}\Delta_{y e}, \\
\mathrm{~mm}\end{array}$ & $\begin{array}{c}P_{y e}, \\
\mathrm{kN}\end{array}$ & $\begin{array}{c}\Delta_{u}, \\
\mathrm{~mm}\end{array}$ & $\begin{array}{c}P_{u}, \\
\mathrm{kN}\end{array}$ & $\mu_{\Delta}$ \\
\hline \multirow{2}{*}{ EJ-4EA-0 } & downward & 26.26 & 58.65 & 67.20 & 53.50 & 2.60 \\
\cline { 2 - 7 } & upward & -25.23 & -56.82 & -67.20 & 58.82 & 2.66 \\
\hline \multirow{2}{*}{ EJ-4EA-1 } & downward & 25.52 & 56.22 & 62.70 & 43.40 & 2.46 \\
\cline { 2 - 8 } & upward & -21.73 & -61.33 & -62.43 & 55.83 & 2.87 \\
\hline \multirow{2}{*}{ EJ-4ES-1 } & downward & 27.18 & 55.99 & 38.00 & 60.20 & 1.40 \\
\cline { 2 - 7 } & upward & -27.23 & -65.26 & -38.00 & -64.73 & 1.40 \\
\hline \multirow{2}{*}{ EJ-6E-0 } & downward & 29.71 & 40.50 & 54.60 & 37.10 & 1.83 \\
\cline { 2 - 7 } & upward & -23.50 & -57.70 & -51.82 & -59.33 & 2.21 \\
\hline \multirow{2}{*}{ EJ-6E-1 } & downward & 38.53 & 75.20 & 57.30 & 74.90 & 1.49 \\
\cline { 2 - 7 } & upward & -31.60 & -79.54 & -50.65 & -78.28 & 1.60 \\
\hline
\end{tabular}

Table 3 shows the displacement ductility factor $\mu_{\Delta}$ of five specimens. It can be observed from Table 3 that $\mu_{\Delta}$ of specimens EJ-4EA-0 and EJ-4EA-1 is greater than that of the remaining three specimens. This can be attributed to the failure mode of specimens EJ-4EA-0 and EJ-4EA-1 differing from that of the other specimens. The formation of the plastic hinge in the beam can enhance the seismic deformation capacity of a structure, so the specimens with plastic hinge failure have higher displacement ductility factors. 
Although specimens EJ-6E-0, EJ-6E-1, and EJ-4ES-1 all exhibited shear failure in the joint core, specimens EJ-6E-0 and EJ-6E-1 were reinforced with high-strength HRB600 bars and thus have higher displacement ductility factors than specimen EJ-4ES-1. This is due to the high yield strain and low elasticity modulus that the high-strength HRB600 bars contribute to the seismic deformation capacity when a specimen fails. Therefore, the utilization of high-strength HRB600 bars can improve the ductility of a specimen.

2.4. Energy Dissipation Capacity. Energy dissipation capacity is an important indicator of the seismic performance of structures and components. It can be estimated from the area enclosed by the load-displacement hysteretic loop. The equivalent viscous damping factor $h_{e}$ is adapted in this paper to measure the energy dissipation capacity of a reinforced reactive powder concrete frame joint. The calculation method is illustrated in Fig. 7 and the equivalent viscous damping factor is defined as

$$
h_{e}=\frac{1}{2 \pi} \frac{S_{A B C}+S_{C D A}}{S_{O B E}+S_{O D F}},
$$

where $S_{A B C}+S_{C D A}$ represents the area enclosed by the loop in the load-displacement response, and $S_{O B E}$ and $S_{O D F}$ represent the area enclosed by the triangles $O B E$ and $O D F$ in Fig. 7.

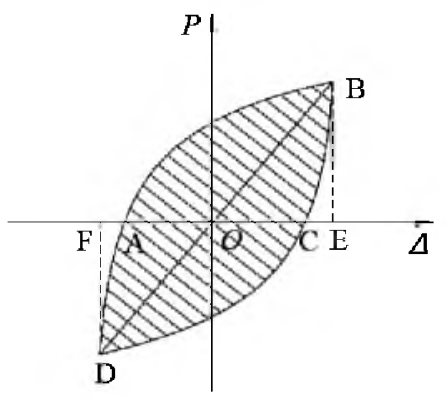

Fig. 7. Calculation for equivalent viscous damping factor.

Table 4 shows the equivalent viscous damping factor of four specimens. It can be observed from Table 4 that the equivalent viscous damping factor of all four specimens ranges from 0.129 to 0.230 , which is higher than that of ordinary reinforced concrete frame joints [14], meaning that reinforced reactive powder concrete frame joints have more energy dissipation capacity. Specimens with plastic hinge failure, such as specimens EJ-4EA-0 and EJ-4EA-1 have larger equivalent viscous damping factors and are thus able to dissipate more seismic energy. Therefore, the design principle of a strong joint and a weak component should be consistently employed in the seismic design of reinforced concrete structures to avoid failure of the joint before the beam. The equivalent viscous damping factors of specimens EJ-6E-0 and EJ-6E-1, which were reinforced with highstrength HRB600 bars were 36.4 and $64.3 \%$ higher than that of specimen EJ-4ES-1. This indicates that the utilization of high-strength HRB600 bars can effectively improve the energy dissipation capacity of a structure.

The energy dissipation capacity increased with the presence of stirrups in the joint core for specimens that exhibited shear failure of the joint. This could be attributed to the confining effect of stirrups on reactive powder concrete, which retarded the propagation of microcracks and deferred the failure process.

2.5. Strength Degradation. The strength degradation of structures and components, which can be expressed by strength degradation factor $\lambda_{j i}$, defined in Eq. (3), represents 
$\mathrm{T}$ a b 1 e 4

Equivalent Viscous Damping Factor of Specimens

\begin{tabular}{|c|c|c|c|}
\hline Specimen & $\begin{array}{c}S_{A B C}+S_{C D A} \\
\mathrm{kN} \cdot \mathrm{mm}\end{array}$ & $\begin{array}{c}S_{O B E}+S_{O D F} \\
\mathrm{kN} \cdot \mathrm{mm}\end{array}$ & $h_{e}$ \\
\hline EJ-4EA-0 & 5914.8 & 4122.7 & 0.228 \\
\hline EJ-4EA-1 & 4725.8 & 3263.5 & 0.230 \\
\hline EJ-4ES-1 & 2084.0 & 2565.0 & 0.129 \\
\hline EJ-6E-0 & 1677.1 & 1516.1 & 0.176 \\
\hline EJ-6E-1 & 4825.3 & 3615.1 & 0.212 \\
\hline
\end{tabular}

the characteristic that bearing capacity of the specimen decreases with the cyclic increase of the reversed load applied to the beam end. Eq. (3) defines $\lambda_{j i}$ as follows:

$$
\lambda_{j i}=\frac{P_{j}^{i}}{P_{j}^{1}},
$$

where $\lambda_{j i}$ is the strength degradation factor in the $i$ th cycle of the $j$ th $\left(j=\Phi / \Phi_{y}\right)$ displacement step and the corresponding peak load is $P_{j}^{i}$, and $P_{j}^{1}$ is the peak load in the first cycle of the $j$ th displacement step.

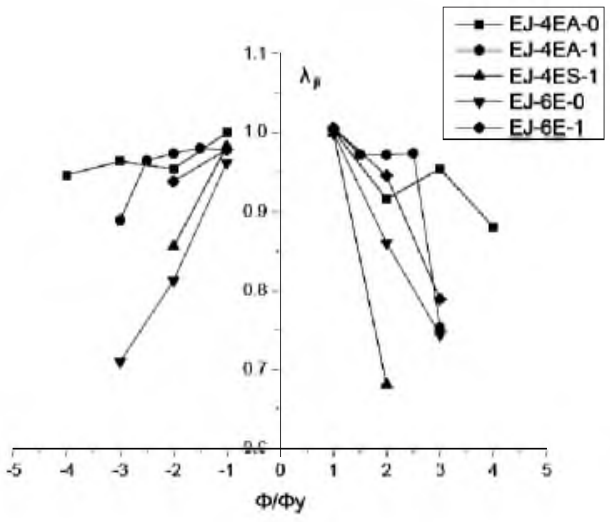

a

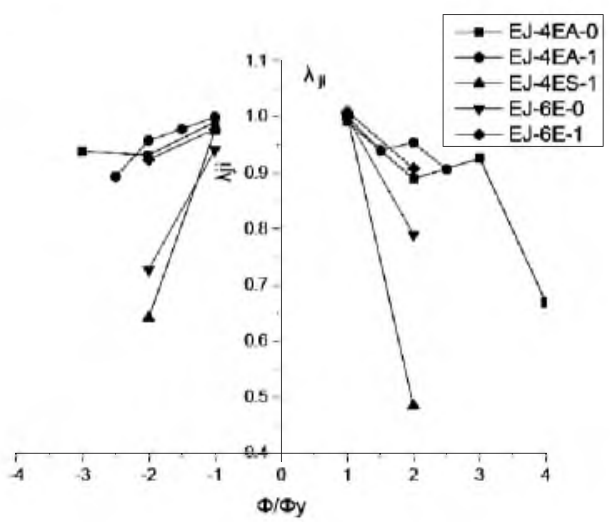

b

Fig. 8. Strength degradation coefficient of specimens; (a) $i=2$; (b) $i=3$.

Figure 8 shows the strength degradation versus deformation $\left(\Phi / \Phi_{y}\right)$ relationship of reinforced reactive powder concrete joints. It can be observed from Fig. 8 that for all specimens, strength degradation was not obvious at the loading stage of $\Phi_{y}$, but a gradual increase began at $2 \Phi_{y}$. The strength degradation of specimens EJ-6E-0 and EJ-6E-1 was far less than that of specimen EJ-4E-1, which could be attributed to the capacity of high-strength steel bars and reactive powder concrete to work well in cooperation. In addition, the stirrups in the joint core provide essential confinement that can retard the development of cracks and degradation of strength in reactive powder concrete. Therefore, the appropriate utilization of stirrups is necessary to achieve the essential confinement of reactive powder concrete. 
2.6. Stuffness Degradation. The stiffness performance of specimens can be assessed by computing secant stiffness, which provides a measure of the stiffness degradation in the specimens [14]. Secant stiffness can be derived as follows:

$$
K=\frac{\sum_{j=1}^{n} P_{j}^{i}}{\sum_{j=1}^{n} \Delta_{j}^{i}}
$$

where $P_{j}^{i}$ and $\Phi_{j}^{i}$ represent peak load and corresponding deformation in the $i$ th cycle of the $j$ th $\left(j=\Phi / \Phi_{y}\right)$ load step, and $n$ represents the number of cycles.

Figure 9 shows the stiffness coefficient versus deformation relations of reinforced reactive powder concrete joint specimens. With the increase of deformation of the beam end, secant stiffness of all specimens gradually decreased, following a similar degradation trend. However, the addition of high-strength HRB600E steel bars caused the rate of degradation of stiffness to decrease compared with HRB400E bars. The use of stirrups in the joint core significantly increased the initial secant stiffness values of the specimens and provided a stable rate of reduction in secant stiffness up to failure.

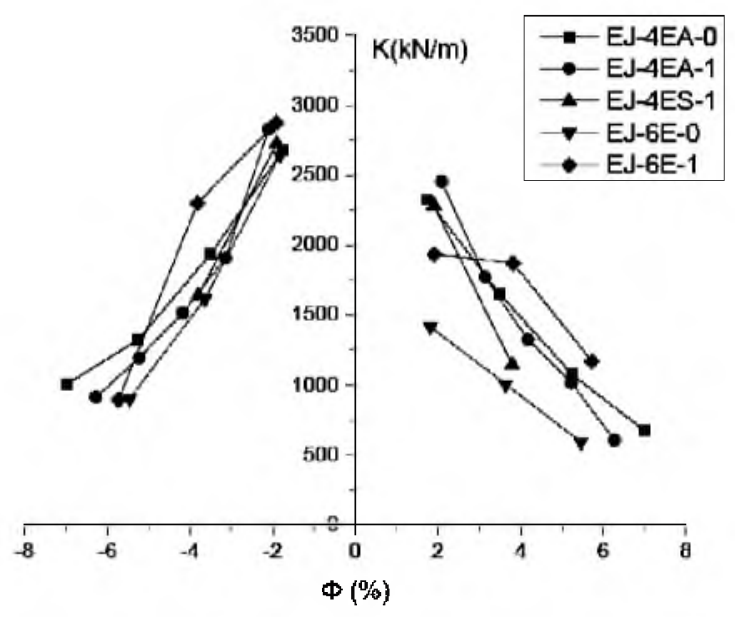

Fig. 9. Stiffness coefficient versus deformation relations of specimens.

2.7. Strain of Stirrup in Joint Core. Figure 11 shows the stirrup strain versus deformation relations of specimens EJ-4EA-1, EJ-4ES-1 and EJ-6E-1. The strains of stirrups in the joint core parallel and perpendicular to the beam length direction are represented by " $-\mathrm{P}$ " and " $-\mathrm{V}$ ", respectively. Before cracking of reactive powder concrete occurred in the joint core, stirrup strains were smaller, usually less than $500 \cdot 10^{-6}$, and unloading could restore the stirrups to their original locations. Stirrup strains in the parallel direction showed a rapid increase and residual deformation after cracking. At the same time, stirrup strains in the perpendicular, or vertical direction developed relatively slowly.

Specimen EJ-4EA-1 acquired only a few small diagonal cracks in the joint core prior to complete failure, and the stirrup in the joint core remained in an elastic stage (Fig. 10a), the maximum strain of which was $1127 \cdot 10^{-6}$.

Stirrup strains in the parallel direction of specimen EJ-4ES-1 quickly increased and exceeded $3000 \cdot 10^{-6}$ in the first cycle of $2 \Phi_{y}$, which represents the tensile yield of stirrups 


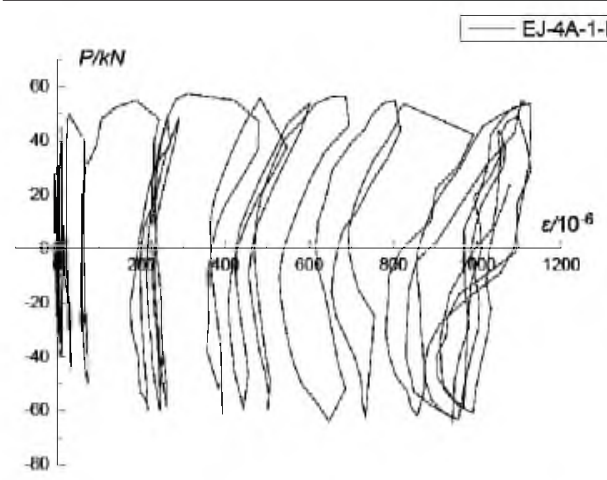

a

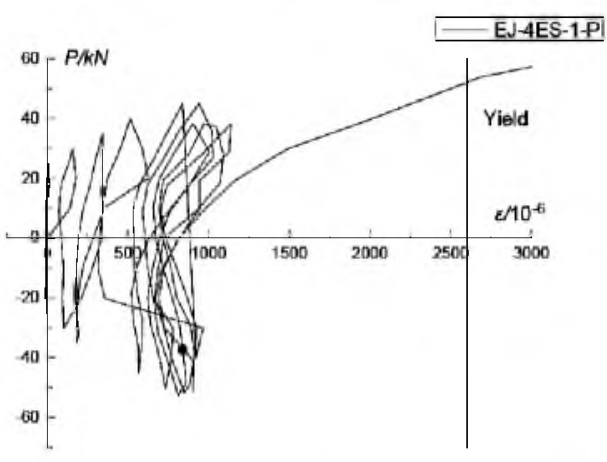

$\mathrm{c}$

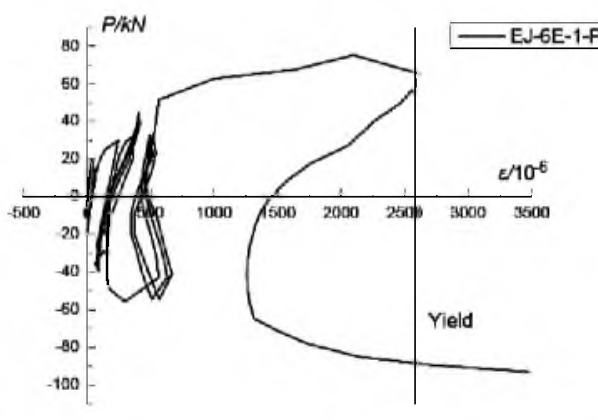

e

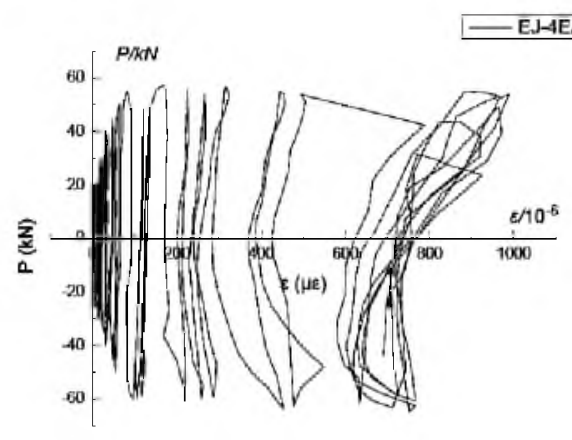

b

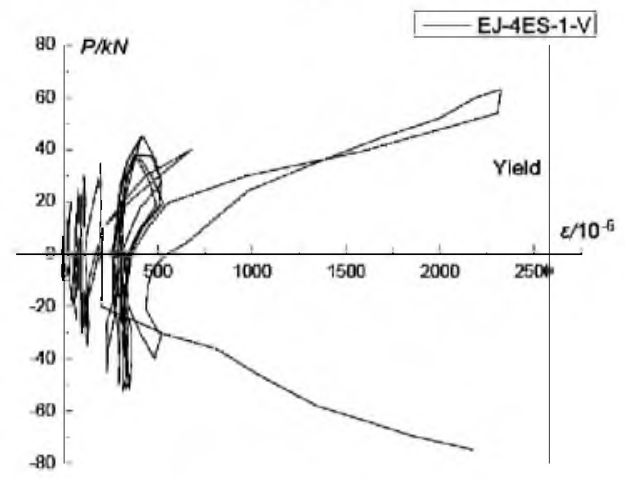

d

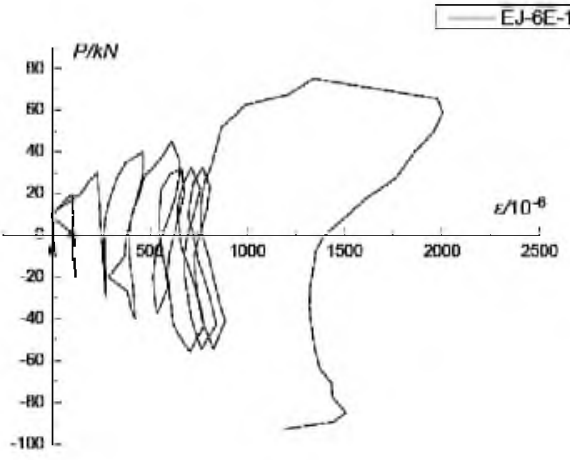

f

Fig. 10. Strain of stirrups in joints.

in that direction, while stirrup strains in the vertical direction were $2317 \cdot 10^{-6}$. With the increase of loading deformation, these strains continued to increase until yield.

When the specimen was subjected to downward (positive) deformation in the first cycle of $2 \Phi_{y}$, stirrup strains in the parallel direction and vertical direction of specimen EJ-6E-1 were approximately $2098 \cdot 10^{-6}$ and $1341 \cdot 10^{-6}$, respectively. Upward (negative) load near the peak caused yield strain in the stirrups in the parallel direction; at this point, stirrup strains in the other direction were $1200 \cdot 10^{-6}$. Stirrup strains in the vertical direction eventually exceeded yield strain at ultimate failure. The experimental results demonstrate that stirrups in the joint core directly bear part of the shear forces while providing essential 
confinement to the reactive powder concrete. Therefore, the use of stirrups in the joint core can increase the shear bearing capacity and energy dissipation capacity of the joint, reduce strength and stiffness degradation, and retard the development of diagonal cracks. In addition, reactive powder concrete has a high tensile deformation capacity, which can enhance the ductility and improve the deformation capacity of joints.

\section{Conclusions}

1. Reinforced reactive powder concrete beam-column joints under reversed cyclic loading exhibit three failure modes: flexural failure of the beam adjacent to the joint core, shear failure of the joint core, and combined failure of the plastic hinge in the beam and shear in the joint core, depending on the reinforcement configuration. Specimens with flexural failure show the best ductility and energy dissipation capacity, while specimens with shear failure have the worst ductility and energy dissipation capacity.

2. High-strength steel bars, such as HRB600E, have relatively high yield strain, and when used as reinforcements can improve deformation and energy dissipation capacity, degradation of stiffness and bearing capacity.

3. The appropriate configuration of stirrups in the joint core can directly bear part of the shear forces and provide essential confinement to reactive powder concrete, thus increasing shear bearing capacity, arresting the development of diagonal cracks, reducing the strength and stiffness degradation and improving the energy dissipation capacity of the joint.

1. G. Zhang, B. Liu, G. Bai, et al., "Experimental study on seismic behavior of high strength reinforced concrete frame columns with high axial compression ratios," Struct. Eng. Mech., 33, No. 5, 653-656 (2009).

2. Z. Fan, L. Xu, and Y. Feng, "Discussion on the application of high-strength reinforcement," Struct. Eng., 29, No. 6, 169-176 (2013).

3. GB 50011-2010. Code for Seismic Design of Buildings, China Building Industry Press, Beijing (2010).

4. C. J. Li, "Development of $600 \mathrm{MPa}$ grade V-N microalloying hot rolled rebar of high performance," Tianjin Metallurgy, 2, 8-10 (2012).

5. P. Richard and M. Cheyrezy, Reactive powder concretes with high ductility and 200-800 MPa compressive strength, in: ACI Spring Convention, SP144-24, American Concrete Institute, San Francisco (1994), pp. 507-518.

6. S. T. Kang, Y. Lee, Y. D. Park, et al., "Tensile fracture properties of an ultra high performance fiber reinforced concrete (UHPFRC) with steel fiber," Compos. Struct., 92, No. 1, 61-71 (2010).

7. D. Mostofinejad, M. R. Nikoo, and S. A. Hosseini, "Determination of optimized mix design and curing conditions of reactive powder concrete (RPC)," Constr. Build. Mater., 123, 754-767 (2016).

8. N. Roux, C. Andrade, and M. A. Sanjuan, "Experimental study of durability of reactive powder concretes," J. Mater. Civil Eng., 8, No. 2, 1-6 (1996).

9. J. Melo, H. Varum, and T. Rossetto, "Cyclic behaviour of interior beam-column joints reinforced with plain bars," Earthq. Eng. Struct. D., 44, No. 9, 1351-1371 (2015).

10. M. Mady, A. El-Ragaby, and E. El-Salakawy, "Seismic behavior of beam-column joints reinforced with GFRP bars and stirrups," J. Compos. Constr., 15, No. 6, 875-886 (2011). 
11. N. Ganesan, P. V. Indira, and M. V. Sabeena, "Behaviour of hybrid fibre reinforced concrete beam-column joints under reverse cyclic loads," Mater. Design, 54, No. 2, 686-693 (2014).

12. ACI Committee 318. Building Code Requirements for Structural Concrete and Commentary, ACI 318M-14, American Concrete Institute, Farmington Hills, MI (2014).

13. BS EN 1998-1: 2004 Eurocode 8. Design of Structures for Earthquake Resistance. General Rules, Seismic Actions and Rules for Buildings, British Standards Institution, London (2004).

14. GJ 101-96. Specificating of Testing Methods for Earthquake Resistant Building. China Building Industry Press, Beijing (1997).

15. B. L. Zhu, Structure Seismic Test, Seismological Press, Beijing (1989).

Received 30. 087. 2016 